\title{
DESIGNING IN RELATIONS:
} SETTING UP A COLLABORATIVE DESIGN 


\section{INTRODUCTION}

"How we change the world" is currently echoing through the design community. It might well be wise to treat such premature promises of salvation with a certain degree of circumspection, but at the same time I am convinced that design can contribute to finding alternative solutions to social and ecological problems. In my opinion, a prerequisite for this is a readiness on the part of designers to engage in constant reflection on themselves and their procedures, and especially to ask themselves: Who is this "WE" in this mission to improve the world? Is this "WE" to be understood exclusively in the sense of "we designers," or does it also encompass participating non-designers?

In participative and collaborative design-in both of which designers work very actively with nondesigners - the goal originally agreed upon often changes in the course of the design process. Codesign projects do not exclusively aim to achieve any single design solution, but endeavour to enable all participants to get to grips with their challenges themselves. A collaboration with a specific community increases sustainability because it has a greater degree of general acceptance from the outset.

Traditional hierarchies among those who create design and those who use it are increasingly being dissolved. "Design among equals" is opening up whole new possibilities of collaboration. According to my understanding, this does not mean that the differences between designers and non-designers are being completely invalidated. "Design among equals" means rather that all participants should address the issue of their own socio-cultural identity and regularly question their own position and their own role.

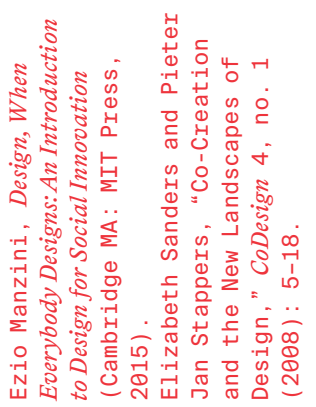

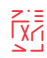

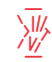

234

This understanding of design as a participative discipline is not new. Design has always been created with and for people. However, the manner in which this "with and for" has been practised in the design process up to now has in recent decades undergone further development, and has become more influential. ${ }^{\gtrless} \mathbb{X}_{\mathrm{N}}^{\mathrm{v}}$ Whereas Genius Design was dominant in the 1980s and in some ways continues to have an impact on the general understanding of design, a design paradigm that entails more open processes and a greater element of participation has meanwhile become firmly established. 铉 
This development can also be observed in the teaching at the Design Department of the Zurich University of the Arts (ZHdK), where students engage very intensively with societal problems and issues. These are often highly complex and require a lively exchange with different interest groups and participants. Besides classical design skills, tools and methods, whole new competences are required. To put it bluntly: co-design processes need not just competent design experts, but also empathetic mentors-someone who can coach in the middle of the process.

Today, lecturers actively need to introduce new competences in "facilitating" in their classes, and must also pose other crucial questions, such as: How can we foster a participative approach to design? What role should the lecturer adopt? How can co-creative processes actually be practised? What should an appropriate design training actually be like in the 21st century?

As a lecturer and researcher in the fields of co-design, video ethnography and design cultures, I should primarily like to share my experiences here of how a participative design approach can be communicated in concrete terms when teaching, and what principles may be derived from it. First, I shall describe how the classroom itself becomes a collaborative experimental space. Next, I shall contrast the old and the new types of expertise to explain how they differ from each other, after which I shall look at the new role of the lecturer. Taking this as my starting point, I shall use the main part of this essay to develop a framework based on five principles that seem especially important to me in communicating and practising participative design. In conclusion, I shall sketch out possible subsequent steps by which the design training at the $\mathrm{ZHdK}$ could be supported and further developed in a focused way. I would argue here that co-design should not be taught exclusively as a method or a tool, but above all as an approach that is actually practised in teaching situations; an approach that will have achieved success at the point where designers or lecturers are no longer needed in the process itself.

\section{THE CLASSROOM AS A COLLAB- ORATIVE EXPERIMENTAL SPACE}

As a lecturer, it is important to me to design my teaching so that the classroom itself becomes an experimental space for collaborative settings. I experience the students as courageous, open, sensitive, and very 
interested in complex social and ecological connections. They want to use their design skills to make a lasting contribution to solving the societal challenges of our time. However, they are not so naïve as to overestimate the modes of action and the scope of what they design.

Collaborative design projects hardly ever fail due to a lack of technological skills. It is rather the soft skills in group-dynamic processes that constitute the biggest hurdles. Thus, in order for teaching to be successful, we above all need a space in which the students can try out their social competences. These include: integrating different interest groups in a team; orchestrating the collaborative process; coping with shifts in perspective and roles; conflict management; and dealing with ambivalence.

The competences that distinguish co-design processes are something you can't teach-they are communicated when lecturers themselves practise them in their teaching. This is active design among equals, without anything being right or wrong. The classroom thereby becomes an open space for experience and experiment, a laboratory and a secure home base for the students. Different things are tried, people rub up against each other, they get to know each other and learn from each other, and intensify their own ability to empathise through a process of joint reflection.

A teaching space that is organised in this manner brings about a fundamental change in the relationship between lecturers and students. As a lecturer, I am challenged to actively fashion this space by trying to create an atmosphere of trust. I moderate; I stimulate. In my activities and actions I live out precisely what is required in collaborative design practices. I become primarily a facilitator of a largescale group. It is my task to invite students to participate in a joint design process. I want to intervene in this process as little as possible, and only as much as is necessary. The goal is to create the appropriate conditions for a collaboration that is as lively and as fruitful as possible. 


\section{EXPERTISE, APPROACH, MINDSET}

In order to be able to practise co-design successfully today, very specific competences are needed. Besides fundamental design expertise, a clear approach and an open mindset are especially important. Designers are increasingly developing from being specialists in designing products to being experts in designing a collaborative creative process. same time, the design discipline has changed overall. Whereas it used to be possible to categorise design study programmes under clearly defined subdisciplines such as graphic design or interior design, today an overarching concept of design for experiences, emotions and interactions is paramount. ()$_{\wedge}^{v / v}$

New fields have emerged in this way, such as "transition design.” $\equiv>>$ We as lecturers face the challenge of anticipating these developments, and of applying methods of human-centred design while developing these further through our teaching. $\frac{v v 1|v|}{1 / x \mid \mathrm{I}}$ Positioning design as a collaborative discipline is closely bound up with the strengthening of specific skills and resources. At the heart of the participatory approach is the curiosity that leads us to explore new things and to open ourselves up to other perspectives in an empathetic manner.

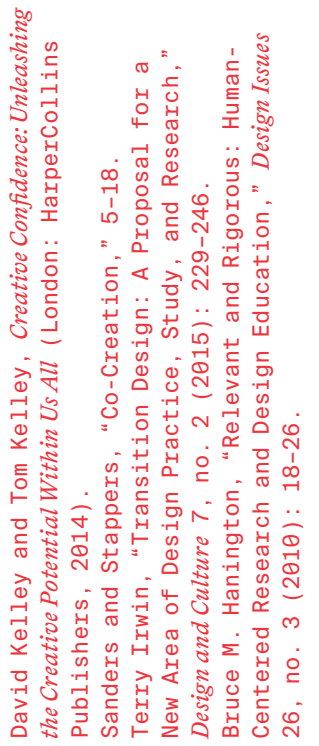

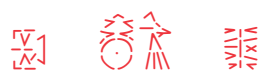

Designers involved in co-creation processes have to be prepared to lay open their work and their approach in a highly proactive manner so that their various cooperation partners will do the same. Only then can a fruitful exchange really take place between different interest groups. This similarly presupposes that students will be sensitised to developing their own canon of values during their training, and that they are also accustomed to constantly questioning that canon. It is just as important for them to maintain their sense of awareness. Enthusiasm, motivational ability, a high degree of self-reflection, a willingness to address conflict and a high tolerance for frustration are also needed in order to design solution-oriented strategies and alternatives. Visual and narrative thinking also play a major role in helping to make complex connections comprehensible to both themselves and others.

Above all, co-design means subjecting accepted hierarchies to critical questioning, engaging with the unpredictable, come what may, and trying out new models of collaboration. 


\section{ARE WE LECTURERS MAKING OURSELVES DISPENSABLE?}

The challenges posed by wanting to change the field of design into a new form of design education can lead to a certain defensive attitude on the part of those with a more traditional understanding of design. One often-heard objection is that today's designers don't learn to design "properly" any more. Even I, admittedly, don't conform to classical designer criteria - I trained in experimental media art, and work as a documentary film maker and as a design coach. Yet being situated at the interface between storytelling, ethnography and design seems to me highly appropriate, especially when it comes to communicating participative approaches.

In my role as a lecturer in the design field, I see myself as a moderator and mentor for individuals and teams. I let the students act, and serve as their sparring partner. Direct, constructive feedback is particularly important in this process. The students have to understand my position and attitude in addition to my constructive criticism, if they are going to profit from our discussions. Disclosing one's own perspectives and principles is vital here. Only in this manner can a fruitful dialogue emerge that has the necessary friction. Setting an example of this oneself enables the students to see it as an invitation to do likewise. In this way, they begin to reflect more and more on their own values and procedures, and by adopting a "helicopter perspective," they become able to recognise possible solutions on their own.

The role of the lecturer here lies in orchestrating different expectations and in the art of making others aware of underlying assumptions during discussions. For example, just what underlies the desire to "change the world," or "I want to help"? Isn't it more sustainable if students acquire the necessary design repertoire that helps them to enable others to take effective action?

Enabling others to find their own, independent solutions will succeed less due to any cognitive interventation than through creating appropriate experiential situations and triggering a change in consciousness. Simulation games in which selected groups of students temporarily assume different behavioural codes offer a good basis for 


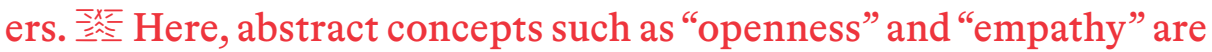
filled with concrete experiences, and a change of perspective is actively rehearsed. Such exercises are immensely important, not least for intercultural collaboration.

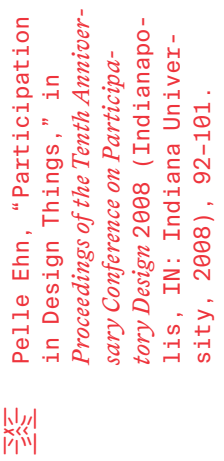

Another possibility is to allow students to slip into an active role as workshop leaders in the context of classes; they can then explore complex issues in which their classmates play the role of a simulated community. This role reversal can provoke a confrontation with aspects of themselves that had remained unknown to them before. Here, issues of self-awareness and outside perceptions are addressed automatically and can be discussed in very specific terms.

This last example makes especially evident the new relationship between lecturers and students. As a lecturer, you assume responsibility for the process organisation of your tuition, but you then consciously delegate this more and more to the students over the course of a project.

This role reversal is a challenge to both sides. Especially at the beginning of their studies, many students believe that they will be provided with the necessary procedures and well-tested toolkits by their lecturer when they start out. They assume that, rather like being given a recipe, they will simply be able to follow the instructions and cook the same dish themselves afterwards. For lecturers, it is difficult to relinquish responsibility for the process and to open themselves up to the unexpected. This can also lead to criticism on both sides and to frustration, on account of feeling overburdened. Lecturers have to live with the fact that there will be more or less explicit demands for them to show greater leadership, and accusations of a lack of expertise. Students have a strong desire to be prevented from making mistakes, just as they have a real need for affirmation from a supposed figure of authority.

In a context of communication and the acquisition of participative methods and co-creative processes, both lecturers and students are required to engage consciously with unpleasant situations. Students sometimes have to bear excessive demands, and lecturers have to put up with the dissatisfaction that will result from this. Ultimately, it is 
not the lecturers who will judge whether a co-design process and its results have been a success, but the users affected by them. This in turn allows us to answer the question as to whether lecturers are hereby "doing away with themselves." The communication of the principles of co-design has been successful if the lecturers have made themselves obsolete at the latest by the end of the process.

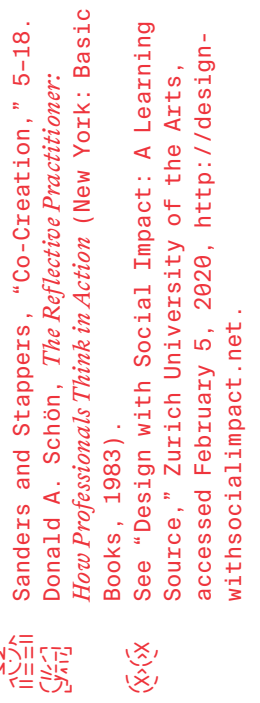

\section{PRINCIPLES FOR AN EDUCATIVE DESIGN REPERTOIRE}

Now that I have described my understanding of how to communicate participative design, and have positioned the classroom as a collaborative, experimental space, I should like to strengthen my case by adding several further principles and by offering some teaching examples. I was inspired in this process by my own teaching experiences, by a reflective practice within the design field and by observations made by Elizabeth Sanders and Pieter Jan Stappers on the four levels of collective creativity and aspects of reflective practice. $\pi=0$

Important elements in co-design, such as empathy, collaboration as equals, respect and openness are easy to list. However, lecturers must be ready to practise what they teach if they want to communicate to budding designers the importance of reflecting on their own approach, their own values and expectations. This is necessary if they are going to build relationships of mutual respect with a new community. What motivates me as a lecturer? What background experience do I bring with me? Where are my boundaries? It is also especially important to address those projects in which we too have stumbled or failed.

The research project "Design with social impact" (x) field of social design with a group of design students from Kenya, Switzerland and Macedonia, in collaboration with various NGOs from the development sector. As the aim was for social design strategies to be grounded in local structures and local expertise, the research group visited Macedonia, where several local seamstresses were provided to help them realise concrete projects. 
We noticed that the seamstresses sat passively at a table and waited for instructions from the students. They, by contrast, were automatically analysing the conditions in Macedonia based on criteria that would have seemed logical in a Swiss context, but that did not fit any known concepts on the spot.

This example illustrates how important it is to actively address the issue of one's own interests, aims and cultural value systems when engaged in collaborative projects. Only when the participants achieve mutual "resonance" does it become possible to develop a common vocabulary and a greater awareness of intercultural differences.

In the context of a principle for design education, the episode described above signifies that in teaching that is participatory in character, the first step should be to establish an open climate for discussion. Lecturers can foster this by themselves demonstrating transparency and by setting a good example-e.g. by recounting their own failures and demonstrating coping strategies for such situations. This can create the desired resonant space that becomes a basis for collaboration and for taking the plunge into co-design.

\section{PRINCIPLE 2-LET IT BE}

If we understand collaborative design as a proactive process, then the right conditions can only arise when everyone is engaged in creating them. Naturally, moments of collaboration must be consciously initiated by the lecturers, and actively maintained by them in the early phase. However, besides actively triggering and orchestrating the co-design process, the challenge is to perceive what further elements arise in the group. Often, it is precisely these unexpected incidents that will later fuel the collaborative process and enable the lecturers concerned to transform their role into something more like a sparring partner and coach. This means that we already need to think such developments through when planning lessons, in order to be able to react as flexibly as possible to issues relating to content and time.

In the study project "Where is Zurich?," a lot of time with their design partners, who, in this project, happened 
to be asylum seekers. I gladly encourage students to embark on this bold step without engaging in much preparatory research, and even without having drawn up a set of participatory methods. Essentially, this is about opening oneself up to others and about developing trust in open processes.

The result of this specific co-design process was a city map of Zurich that covered places and activities that require no money, or at least very little. This concept allowed for the map to be expanded by the asylum seekers themselves. In this way, the students were able to liberate themselves more and more from their roles during the development of the project-and the same applied to me, their lecturer. This open-ended, exploratory approach can create a high degree of acceptance and sustainability, both in co-design projects and in collaborative teaching. In both situations, this opening up of oneself without any fixed procedural plan needs both practice and constant work to develop a set of collaborative methods. One of the biggest challenges for lecturers and students alike is that this consciously practised openness awakens hopes among the cooperation partners that cannot be realised later. This fact has to be actively addressed in both scenarios, right from the start.

PRINCIPLE 3-LEARNING BY DOING

Many students are influenced by an educational model that is oriented on the following logic: only they who have learned everything will be allowed to embark on concrete projects. In co-design, however, the complete opposite is the case. Only when I actively set off with a group of different participants can I begin to understand everyone's needs and the underlying conditions and possible solutions. The learning process is thus driven by joint "doing." This applies equally to the design setting and the teaching setting. The advantage of beginning with this straight away also lies in the fact that the group does not fall into paralysis. It can help to have a knowledge of appropriate collaborative methods (role-playing, bodystorming, etc.), techniques (e.g. storytelling) and materials (e.g. toy bricks, plasticine). A joint awareness of the overall 
process can also help, based on which the participants agree on a suitable process model and the location and documentation of the individual work stages and project phases. This can help to create a sense of orientation and to clarify expectations.

One study group investigated the topic "Taking a break" at the Heuried community centre. dren are romping about on the playground? Conversations with parents provided several important hints about behaviour in the playground. In order to grasp the children's perspective properly, the students had to employ methods other than interviews. So they mounted cameras on helmets for the children to wear. This meant they were not only able to immerse themselves in the children's world, but that only by doing different things could the overall experiment develop a certain dynamic of its own. The children loved their new roles as little cameramen and camerawomen. Inspired by this, the students then developed a doll with a camera and a radio, which they hid on the playground as an independent observer.

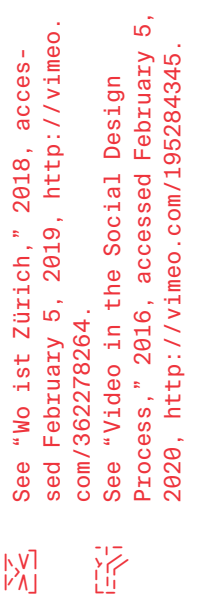

This combination of doing, reflecting and doing again is a core driver of collaborative processes. These shared experiences also help us to decide on subsequent steps. For example, by constantly putting ideas into concrete form-whether in a co-design project or in teaching - the group members acquire a core instrument that enables them to press ahead with the collaborative process, and to fine-tune their exchange of ideas in the face of the concrete manifestation of a prototype.

\section{PRINCIPLE 4-STORYTELLING AS SYNTHESIS}

In work discussions, students often expect their lecturers to provide quite concrete solutions to problems. However, instead of presenting finished solutions, collaborative procedures provide an opportunity to run through the synthesis process in the form of different scenarios. Students are encouraged to package a problem in a story and to tell it systematically from different perspectives. This compels them to translate abstract solutions into illustrative speech.

In a further co-design project, entitled "Jetpack game," the students actively worked together with patients in a psychiatric clinic. 
of the project, the patients were nervous and not yet ready to collaborate. The students were unable to cope with this situation, and the project faltered. As their lecturers, we did not focus on the apparent impasse, instead urging the students to tell us about the nervousness they saw, but from the perspective of the patients. These stories made it possible for them to engage with the patients in a far more concrete way, and to jointly explore different perspectives on the same situation. This act of storytelling enabled them to dismantle hurdles and to collaboratively develop a card game that they were able to employ as a trust-building measure in the design process.

Narrative methods support this joint process of synthesis. They help us to make complex issues and moods highly comprehensible by means of illustrative descriptions. Storytelling helps participants to adopt different perspectives and to negotiate convincing scenarios in a collaborative manner. When there are seemingly insurmountable disagreements and hurdles that one cannot easily describe in words, and which in turn make it difficult to take the important decisions needed to make progress, then narrative techniques such as video prototyping can help to move things forward.

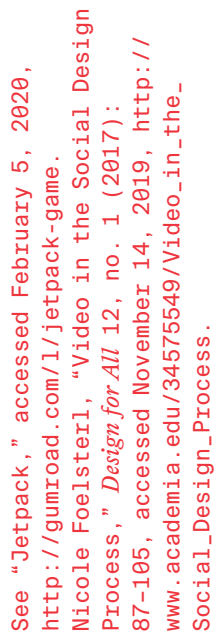

\section{LIVING COLLABORATIVE DESIGN}

Many forms of participative and collaborative design are practised actively and successfully at the ZHdK. Students of all disciplines have already set up successful co-design projects. It seems to me more sustainable when this approach is practised from the ground up, actively, by students themselves, and when it is directly included by lecturers in their teaching. A modern design curriculum should be transparent and flexible in order to be able to incorporate collaborative endeavours where appropriate. This does not mean that these endeavours should be institutionalised, but that the right framework should be created to make such practical collaborations possible on all levels.

闹䋔 As a lecturer who is at home in different disciplines, I engage inten-
sively with the appropriate strategies for communicating collaborative 244

approaches, methods and tools. The present essay has 
condensed my experiences in four core principles that have provided me with a means of orientation which, in turn, helps me to further develop my co-design teaching. What is more, these principles have in recent years had a long-lasting impact on my understanding of my role as a lecturer, on how I interact with students, and on how I communicate the content of what I teach.

I am convinced that we design educators will increasingly have to adapt our position and our role in order to be open to the changes that will arise from a greater integration of collaboration into what we do.

As lecturers, we are faced with the challenge of practising what we expect from the students, and of doing this on their level, on an equal footing. A certain degree of uncertainty and even failure is part and parcel of this; in return, this can empower us to achieve huge developmental advances.

Just as co-design can change students and lecturers alike, I even venture to hope that it can have a lasting impact on the culture of "togetherness" at the $\mathrm{ZHdK}$ as a whole. Design among equals will bring forth new working models and will make us completely rethink hierarchies. Co-design possesses the innovative power not merely to draw our attention to the power of collaboration, but to actively shape that collaboration. The Department of Design and the $\mathrm{ZHdK}$ as a whole can become an active space for encounters and relationships. In that sense, this article should be understood as an invitation to utilise co-design approaches to continually develop ourselves further as lecturers and as an institution, together with the students, and to be living examples of participation in the here and now. 



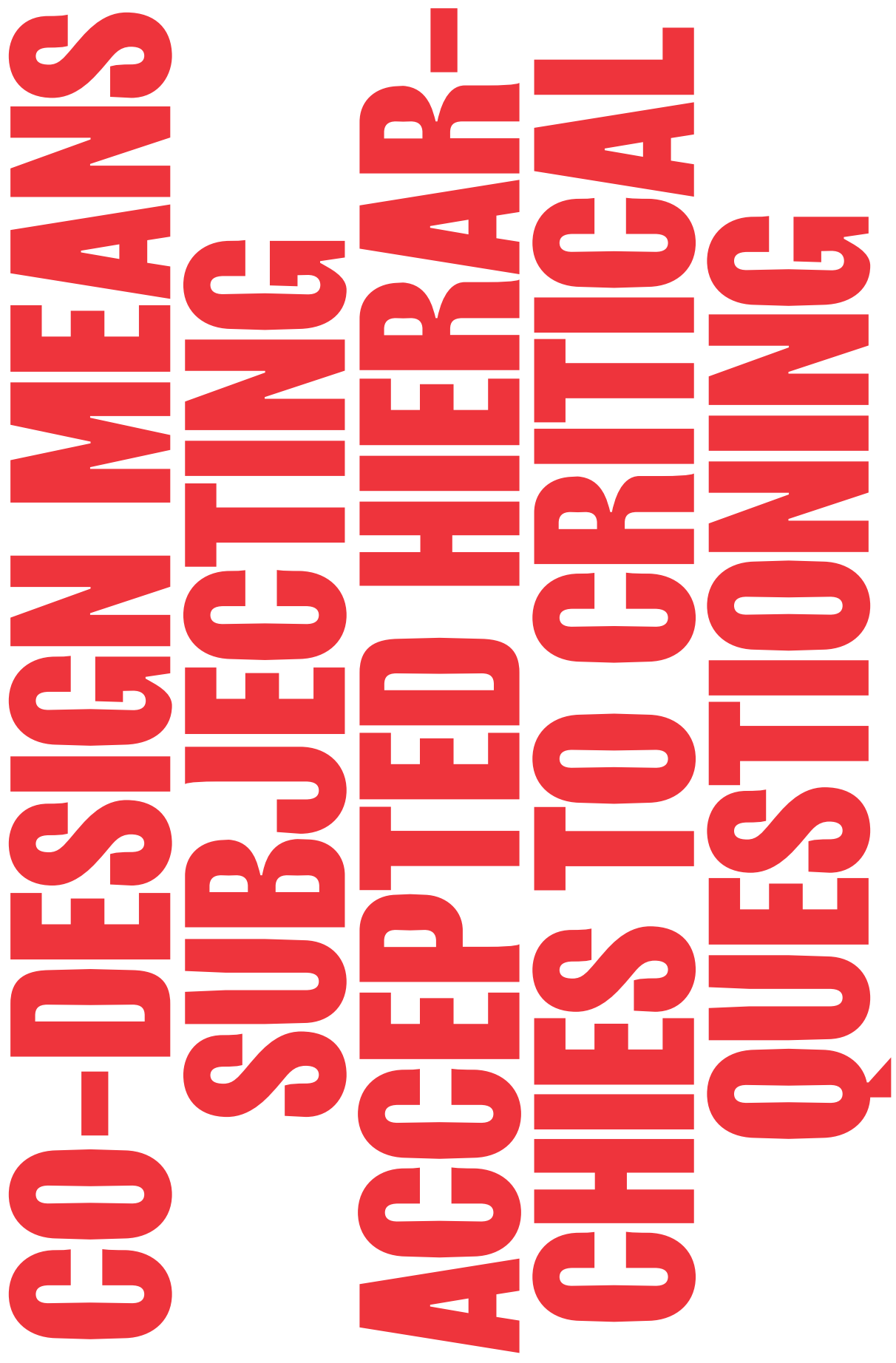

HIERARCHIES

P. 234

P. 237

P. 245

P. 352

P. 470

CRITICAL

P. 56

P. 64

P. 77

P. 79

P. 84

P. 85

P. 115

P. 116

P. 117

P. 120

P. 129

P. 154

P. 221

P. 237

P. 270

P. 321

P. 324

P. 329

P. 353

P. 370

P. 377

P. 430

P. 432

P. 446

P. 454

P. 460

P. 468

QUESTIONING

P. 237

P. 252

P. 324

P. 376

P. 447 
